- Harris JO, Swenson EW, Johnson JE 3rd. Human alveolar macrophages: comparison of phagocytic ability, glucose utilization, and ultrastructure in smokers and nonsmokers. $\mathcal{F}$ Clin Invest 1970;49:2086-96.

7 Warr GA, Martin RR. In vitro migration of human alveolar macrophages: effects of cigarette smoking. Infect Immun 1973;8:222-7.

${ }^{8}$ Yeager H Jr, Zimmet SM, Schwartz SL. Pinocytosis by human alveolar macrophages. Comparison of smokers and nonsmokers. 7 Clin Invest $1974 ; 54: 247-51$.

- Reynolds HY, Newball HH. Analysis of proteins and respiratory cells obtained from lungs by bronchial lavage. 7 Lab Clin Med 1974;84:55973.

${ }^{10}$ Hunninghake GW, Gadek JE, Kawanami O, Ferrans VJ, Crystal RG. Inflammatory and immune processes in the human lung in health and disease: evaluation by bronchoalveolar lavage. Am $\mathcal{f}$ Pathol 1979;97: 149-205.

11 Cole P, Turton C, Lanyon $\mathrm{H}$, Collins J. Bronchoalveolar lavage for the preparation of free lung cells: technique and complications. $\mathrm{Br} \mathcal{F} \mathrm{Dis}$ Chest $1980 ; 74: 273-8$

12 Greening AP, Lowrie DB, Poole GW. Bronchoalveolar lavage in pulmonary diseases including sarcoidosis. Br $\mathcal{F}$ Dis Chest $1981 ; 75: 321$.

${ }^{13}$ Reynolds HY, Fulmer JD, Kazmierowski JA, Roberts WC, Frank MM, Crystal RG. Analysis of cellular and protein content of bronchoalveolar lavage fluid from patients with idiopathic pulmonary fibrosis and chronic hypersensitivity pneumonitis. $\mathcal{F}$ Clin Invest 1977;59:165-75.

${ }^{14}$ Haslam PL, Turton CWG, Heard B, et al. Bronchoalveolar lavage in pulmonary fibrosis: comparison of cells obtained with lung biopsy and clinical features. Thorax $1980 ; 35: 9-18$.

15 Hunninghake GW, Kawanami O, Ferrans VI, Young RC Jr, Roberts WC Crystal RG. Characterization of the inflammatory and immune effector cells in the lung parenchyma of patients with interstitial lung disease. Am Rev Respir Dis 1981 ;123:407-12.

${ }^{16}$ Crystal RG, Gadek JE, Ferrans VJ, Fulmer JD, Line BR, Hunninghake GW. Interstitial lung disease: current concepts of pathogenesis, staging and therapy. Am $\mathcal{F}$ Med $1981 ; 70: 542-68$.

17 Crystal RG, Fulmer JD, Roberts WC, Moss ML, Line BR, Reynolds HY. Idiopathic pulmonary fibrosis: clinical, histologic, radiographic, physiologic, scintigraphic, cytologic, and biochemical aspects. Ann Intern Med $1976 ; 85: 769-86$

${ }^{18}$ Rudd RM, Haslam PL, Turner-Warwick M. Cryptogenic fibrosing alveolitis. Relationships of pulmonary physiology and bronchoalveolar lavage to response to treatment and prognosis. Am Rev Respir Dis 1981;124: 1-8.

19 Weinberger SE, Kelman JA, Elson NA, et al. Bronchoalveolar lavage in interstitial lung disease. Ann Intern Med 1978;89:459-66.

${ }^{20}$ Crystal RG. Skin testing, blood studies, and bronchoalveolar lavage to assess activity of pulmonary sarcoidosis, pp 81-3. In: Crystal RG, moderator. Pulmonary sarcoidosis: a disease characterized and perpetuated by activated lung T-lymphocytes. Ann Intern Med 1981;94:73-94.

${ }^{21}$ Gadek JE, Fells GA, Crystal RG. Cigarette smoking induces functional antiprotease deficiency in the lower respiratory tract of humans. Science $1979 ; 206: 1315-6$

${ }^{22}$ Hoidal JR, Fox RB, LeMarbe PA, Perri R, Repine JE. Altered oxidative metabolic responses in vitro of alveolar macrophages from asymptomatic cigarette smokers. Am Rev Respir Dis 1981;123:85-9.

\section{Electron microscopy: an essential tool for morphological diagnosis?}

The importance of the electron microscope in medical research has been well recognised and universally accepted for at least three decades. What, perhaps, has not been widely recognised so far is the part the instrument can play in routine pathology laboratories. One well-known text on general pathology, for example, stated in 1977 in its section on the interpretation of needle biopsy specimens of the liver that electron microscopy was not yet used in routine laboratories. ${ }^{1}$ Since then the need to examine tissue electronmicroscopically has become more generally acknowledged, since such studies can be of direct value in the management of patients. ${ }^{2}$

The value of electron microscopy is shown by a recent report of its use in 49 neoplasms including poorly differentiated carcinomas and sarcomas, lymphomas, and amelanotic melanomas. The diagnosis achieved by light microscopy was compared with the ultrastructural changes. The results showed that in 40 of the 49 cases ( $82 \%$ ) electronmicroscopical examina- tion confirmed the tentative diagnosis made at light microscopical level. In 11 of the $\mathbf{4 0}$ cases more specific diagnosis was possible. In $6 \%$ (three cases) the original light microscopical diagnosis had to be corrected. In two patients even electronmicroscopical examination failed to resolve the problem.

Kuzela et $a l^{2}$ considered the more precise histogenetic diagnosis clinically helpful in $56 \%$ of cases studied. They inquired about the value of the instrument in the eyes of a surgeon, a radiotherapist, and a medical oncologist. In $38 \%$ of cases all three clinicians agreed that electron microscopy would influence patient management. In an additional $18 \%$ one of the three clinicians considered electronmicroscopical examination to be of practical significance. In the remaining $44 \%$ this form of investigation was considered irrelevant. The authors concluded that electronmicroscopical evaluation forms a beneficial adjunct to the correct diagnosis in selected tumours, permitting more specific features to be examined in identifying the cell of origin in poorly differentiated neoplasms.

The electron microscope is not only useful in the context of patient management in evaluation of the pathological features of tumours. The instrument has also proved of great value in certain other fields: examination of renal biopsy specimens, for example, has not only led to a more precise diagnosis but has also permitted evaluation of tissue not possible on conventional light microscopical examination. This also applies to tissue from other organs including the heart.

Though needle biopsies of the heart have been undertaken, ${ }^{3}$ the bioptome, ${ }^{45}$ an instrument which is essentially a catheter with a cutting device at one end and an operating handle at the other, has been used with increasing frequency in evaluating endomyocardial tissue. ${ }^{6}$ This is another area where electronmicroscopical examination in combination with light microscopy is important and contributes substantially to more precise morphological diagnosis and thus to patient management.

Several examples spring readily to mind. Despite many staining techniques available for the detection of amyloid in the heart (and other organs) at light microscopical level, electron microscopy affords the most accurate assessment. Another example where electron microscopy has proved to be of inestimable value is in the accurate diagnosis of conditions such as Fabry-Anderson disease. ${ }^{7}$

One of the best-recognised applications of electron microscopy in patient management is in the administration of agents such as Adriamycin, or doxorubicin, which have been used for their antineoplastic effect on a broad spectrum of malignant diseases. Unfortunately patients may develop cardiotoxicity with long-term repeated treatment, particularly if the cumulative dose of $500 \mathrm{mg} / \mathrm{m}^{2}$ is exceeded or if the drug is administered in combination with radiation therapy. By means of endomyocardial biopsy the cardiotoxic changes can be accurately assessed and doses of the cytotoxic agents can be monitored, permitting the maximum amount of drug to be administered with the minimum risk of heart failure. ${ }^{8}$

More accurate evaluation can also be made of possible degenerative changes in patients diagnosed clinically and at light microscopical level as suffering from myocarditis. ${ }^{9}$ Preliminary results of sequential biopsies on these patients have shown the beneficial effect of administration of corticosteroids or immunosuppressive agents or both.

One field of cardiological pathology where electron microscopy has proved to be a major diagnostic tool is in the evaluation of eosinophils in patients with suspected endomyocardial disease associated with eosinophilia. It has become recognised 
that associated endomyocardial disease occurs if a substantial number of eosinophils are degranulated. Though special staining may show these abnormal cells at histological examination, degranulation may be so severe that assessment of the abnormal cells can only be made at electronmicroscopical level. This has been my experience in isolated cases.

Electronmicroscopical evaluation has also been undertaken on cardiac tissue in assessing prognosis in patients with dilated (congestive) cardiomyopathy. ${ }^{1011}$ Degrees of hypertrophy can also be more accurately assessed..$^{12}$ It has also been used in an effort to find a morphological explanation for the clinical manifestations of hypertrophic cardiomyopathy, ${ }^{13}$ though its diagnostic value at that level of investigation is controversial. ${ }^{14}$

So far as primary diagnosis is concerned examination by electron microscopy alone is of limited value. Even so, in combination with light microscopical examination, this level of morphological analysis can be of great value; the electron microscope should now be accepted as an important component in routine pathology laboratories.

E G J OLSEN

Consultant Pathologist,

National Heart Hospital,

London W1M 8BA

1 Anderson WAD, Kissane JM, eds. Pathology. Vol 2. 7th ed. St Louis: Mosby, 1977:1329.
${ }^{2}$ Kuzela DC, True LD, Elseman B. The role of electron microscopy in the management of surgical patients. Ann Surg 1982;195:1-11.

${ }^{3}$ Shirey EK, Hawk WA, Mukerji D, Effler DB. Percutaneous myocardial 3 biopsy of the left ventricle. Experience in 198 patients. Circulation 1972; $46: 112-22$.

4 Konno S, Sakakibara S. Endo-myocardial biopsy. Diseases of the Chest 1963;44:345-50.

5 Richardson PJ. King's endomyocardial bioptome. Lancet 1974;i:660-1.

6 Olsen EGJ. Myocardial biopsy. In: Hamer J, ed. Recent advances in cardiology. Vol 7. Edinburgh: Churchill Livingstone, 1977:349-67. क

${ }^{7}$ Desnick RJ, Blieden LC, Sharp HL, Hofschire PJ, Moller JH. Cardiac valvular anomalies in Fabry disease. Clinical, morphologic, and bio-e chemical studies. Circulation 1976;54:818-25.

${ }^{8}$ Billingham ME, Mason JW, Bristow JR, Daniels JR. Anthracycline $\overrightarrow{\overline{\vec{G}}}$ cardiomyopathy monitored by morphologic changes. Cancer Treat Rep $\frac{\text { T }}{9}$ 1978;62:865-72.

${ }^{9}$ Daly K, Richardson PJ, Olsen EGJ, Pattison J, Jackson G, Jewitt DE. 흐 Immunosuppressive therapy in acute inflammatory myocarditis. $\bar{\omega}$ Circulation $1981 ; \mathbf{6 4}$,suppl IV:IV-27.

${ }^{10}$ Kuhn H, Breithardt G, Knieriem JH, et al. Prognosis and possible $\varrho$ presymptomatic manifestations of congestive cardiomyopathy (COCM). Postgrad Med F 1978;54:451-61.

11 Baandrup U, Florio RA, Roters F, Olsen EGJ. Electron microscopic $\overrightarrow{0}$ investigation of endomyocardial biopsy samples in hypertrophy and $\overrightarrow{-}$ cardiomyopathy. A semiquantitative study in 48 patients. Circulation $\vec{\omega}$ $1981 ; 63: 1289-98$.

12. Olsen EGJ. Structural and ultrastructural basis of myocardial disease. 을 Proc $R$ Soc Med 1976;69:195-7.

${ }^{13}$ Ferrans VJ, Morrow AG, Roberts WC. Myocardial ultrastructure in idiopathic hypertrophic subaortic stenosis. A study of operatively excised left ventricular outflow tract muscle in 14 patients. Circulation $1972 ; 45:$ 769-92.

14 Olsen EGJ. The pathology of idiopathic hypertrophic subaortic stenosis (hypertrophic cardiomyopathy). A critical review. Am Heart f $1980 ; \vec{\infty}$ 100:553-62.

\section{Regular Review}

\section{Primary biliary cirrhosis}

\section{R TRIGER}

Until recently primary biliary cirrhosis was considered to be a rare disorder characterised by chronic cholestasis, pigmentation, xanthomatous eruptions, and histological features of chronic non-suppurative destructive cholangiohepatitis. The classic presenting feature is generalised pruritus in a middleaged woman, usually preceding jaundice; and the disorder is then chronic and progressive, leading to death from liver failure or the complications of portal hypertension within five to seven years. With the discovery of the antimitochondrial antibody and its diagnostic specificity in liver disease, however, the disease has acquired a broader aspect. Many cases lack both the typical clinical and histological features. Indeed, primary biliary cirrhosis is now being diagnosed with increasing frequency, and in many English liver clinics it is arguably the most common cause of cirrhosis in middle-aged and elderly women. This observation prompted several epidemiological studies which formed the basis of a workshop reported in a leading article in the $B M \mathcal{F}$ last year. ${ }^{1}$ Interest has been further aroused by a report that environmental factors might play a part in the pathogenesis of primary biliary cirrhosis, ${ }^{2}$ and a multinational inquiry into the incidence and prevalence of the disease is being mounted ${ }^{2 a}$ in the hope that it may help to shed light on its aetiology.

The two laboratory abnormalities most commonly asso- 0

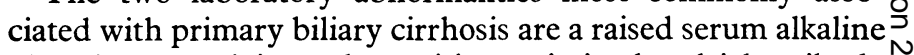
phosphatase activity and a positive antimitochondrial antibody o test result. As requests for routine biochemical and auto- $\frac{D}{0}$ immune profiles have become more common many patients are being found to have early presymptomatic liver disease. ${ }^{3}$ Some O patients have even been described with unequivocal histo- $\omega$ logical evidence of primary biliary cirrhosis in whom serum bilirubin, alkaline phosphatase, and transaminase values were entirely normal, though in most such cases abnormalities could $\stackrel{\Phi}{\Phi}$ be found in serum IgM and gammaglutamyltransferase. On the other hand, several groups have reported asymptomatic

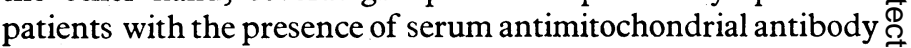
and no biochemical or histological evidence of primary biliary $\underset{\mathbb{Q}}{\Omega}$ cirrhosis. ${ }^{4-6}$ Presumably many of these patients may ultimately무 develop the clinical disease which we recognise as primary $\delta$ biliary cirrhosis, but the rate at which this occurs is highly을 variable, and the stimuli initiating this process are unknown.흘 Our present knowledge suggests that genetic, infective, $\stackrel{?}{?}$ 